\title{
Disability citizenship: an Australian human rights analysis of the cultural industries
}

Simon Darcy* and Tracy Taylor

University of Technology Sydney, of Leisure, Sport and Tourism, Eton Rd, Lindfield 2070,Australia

*Corresponding author. Email: simon.darcy@uts.edu.au

(Received 20 January 2009; final version received 27 May 2009)

\section{Reference details}

Darcy, S., \& Taylor, T. (2009). Disability citizenship: An Australian human rights analysis of the cultural industries. Leisure Studies, 28(4), 419-441.

\begin{abstract}
Research on disability and cultural life (the arts, leisure, recreation, sport and tourism) in the Australian context has largely been captured by medical approaches to disability. In contrast, this paper takes direction from social approaches to disability that place the experience of people with disabilities at the centre of the research paradigm by examining this population's human rights' experiences. The paper is framed by reviewing the United Nations' disability initiatives including the Convention on the Rights of People with Disabilities. The research then analyses the implementation and operation of Australia's Disability Discrimination Act, 1992 (DDA) in respect to the cultural life of people with disabilities. The research design uses a mixed method interpretive approach drawing on the management information systems of the Human Rights and Equal Opportunity Commission and the Federal Court. The analysis of 420 complaint cases and 80 Federal court actions show a relationship between the types of discrimination experienced in cultural life and gender, disability type and industry sector. The recurring themes of discrimination demonstrate an ongoing struggle by people with disabilities to assert their rights of citizenship.
\end{abstract}

Keywords: disability discrimination; cultural life; citizenship; human rights

\section{Introduction}

Cultural life, as defined by the United Nations Convention on the Rights of People with Disabilities (2006), is an important part of any person's citizenship. As the United Nations outline, whether it be recreation, leisure, the arts, sport or tourism it is the enriching part of people's lives where they strive to express themselves away from the everyday reality of their existence. People with disabilities (PwD) are no different, where cultural life has been identified as a very important part of their existence (Barnes, Mercer, \& Shakespeare, 1999). As Stebbins (2006) and others have argued, for some individuals and groups of PwD, cultural life plays a far more important role as they have been denied active citizenship through employment. Cultural life has become the 'serious' focus of their existence (Patterson \& Lobo, 2000; Shaw \& Dawson, 2001; Stebbins, 2000). Yet, a great deal of research has focused on the medicalised benefits of 
active physical involvement for $\mathrm{PwD}$ due to lower levels of participation than the general population (e.g. Cooper et al., 1999). While a very important consideration, participation in cultural life is more than physical activity and exercise with prescribed therapeutic outcomes.

This research is based on a social approach to disability that places the lived experience of PwD at the centre of the research paradigm (Kitchin, 2000; Oliver, 1996). The position of PwD within the research process has always been contested by social constructionists and there has been controversy within leisure studies as to the position of the researcher and the subjects of research (Henderson, Bedini, Hecht, \& Schuler, 1995; Smears, 1996) where the position of researchers in gender, race and sexuality research has been far more considered (e.g. Hylton, 2005; Meekosha, 2006). Central to the understanding of a social approach to disability is the consideration of the individual and their impairment within the socially constructed disabling environments. As more contemporary understandings of the social model suggest, the consideration of the embodiment of individuals within cultural life is essential to understanding the complex interplay between impairment, disability and environment, and hence, how the disability experience is constructed (Packer, McKercher, \& Yau, 2007; Shakespeare \& Watson, 2001; Thomas, 2004).

\section{Statement of the problem and research design}

While Australia is signatory to international human rights agreements regarding disability and implements these legal responsibilities through the Disability Discrimination Act, 1992 (DDA), what signifies inclusive citizenship is the way that these rights affect the day-to-day lives of PwD (Gleeson, 1999; Meekosha \& Dowse, 1997, 2001; Priestley, 1998; Tiddy, 2001). This paper seeks to contribute to this 
understanding by using a mixed method interpretive approach by firstly reviewing the approaches to including PwD in cultural life. Second, the paper places this review in context of the United Nations (UN) human rights initiatives relevant to disability and cultural life, and how Australia has implemented the DDA over of its 15 year history (1993-2008). Third, the paper analyses the publicly available outcomes of complaint cases $(n=420)$, HREOC hearings and Federal court actions $(n=80)$ brought under the DDA to investigate quantitatively and qualitatively whether there were emergent patterns of discrimination and reoccurring themes to any patterns of discrimination.

The quantitative analysis of the complaint cases was developed through reading the cases, developing a systematic approach to their analysis and entering the data into the Statistical Package for the Social Sciences (SPSS v16) organised into the following variables: year; type of disability/dimension of access (defined by DDA); industry sector (defined by Lynch and Veal 2006); business type (defined by ABS 2007 \& Lynch and Veal 2006); category of discrimination (defined by DDA); entity bringing case (defined by DDA); gender; and outcome and compensation (defined by DDA). The quantitative analysis involved frequencies, cross tabulations and Chi-square tests for independence. Lastly, the qualitative analysis utilised an interpretive approach to analyse reoccurring themes affecting PwD's cultural life. The qualitative analysis involved a constant comparison (Glaser \& Strauss, 1967) of the complaint case circumstances, the spirit and intent of the DDA and social approaches to disability (Aitchison, 2003; Barnes et al., 1999; Oliver, 1996).

\section{Approaches to Cultural life}

In the last twenty years many Western countries have adopted their own disability discrimination legislation, which includes the right to cultural life. Professionals 
involved in cultural service deliver have argued that a satisfying cultural life has a significant contribution to the well-being of individuals and improves the quality of life of society generally. When PwD participate in cultural activities they obtain the same benefits as the rest of the community. However, it has been recognized internationally that PwD generally have lower participation rates in all forms of cultural life than the general community (Cozzillio \& Hayman, 2005; Darcy, 2002; Rimmer, Rubin, \& Braddock, 2000). Participation is a complex interaction between intrapersonal, interpersonal and structural factors. If access is inhibited or denied then the benefits are only potential rather than actual.

Cultural practices for PwD reflect the historical contexts faced by this group (Aitchison, 2003). Generally, the first uses of organised cultural interventions occurred in institutional environments. These were largely with people with intellectual impairments, blind people and those with mental health issues. The activities were wholly segregated, took place within the institutions and were used to manage 'free time', boredom and the uniformity of institutional life (Lockwood \& Lockwood, 1999). During the late 1960s and early 1970s the first independent living movements were gaining momentum and sought to bring about de-institutionalization of these groups into the community. With the advent of de-institutionalization came the introduction of the mainstreaming of cultural experiences. This was based on the integration of PwD into community based activities. However, this integration was often physical rather than social whereby these activities took place in community settings but were socially separate from the community (Devas, 2003) . These approaches were based on PwD's cultural experience being regarded as 'special' and were seen as being apart from rather than as a part of the community experience. 
A community development approach sought to develop mainstream and inclusive experiences that facilitated PwD participating in cultural activities with other members of the community (Lockwood \& Lockwood, 1999). More important than the participation fostered was the development of relationships it established. These relationships are interdependent, involve $\mathrm{PwD}$ in all roles (participant, volunteer, committee member etc.) and aim to empower PwD to make informed choices. The relationships are an important component of the rights of citizenship. As Hutchinson (1997, p. 3) suggests “citizenship is much more than: rights + empowerment + inclusion + getting a life. It is a more intangible concept that includes all of these things, but something more. It is at the core of what it is to be human.”

Accessibility and inclusion are the foundations of citizenship and participation in cultural life for PwD. In the past the provisions for PwD in cultural life were viewed as an extension of other community participation through the provision of special needs (Devas, 2003). As Darcy (2001, p. 75) suggests, universal design offers the potential to move away from the provision of 'special needs' and provide sustainable development for all members of the community over their lifespan. Universal design by definition incorporates planning and design of products and environments usable by all people, to the greatest extent possible, without the need for adaption or specialized design (see Center for Universal Design, 2009 for an illustrated explanation of the 7 principles). Universal design by principle seeks to maximize community participation through targeting people of all ages, genders, sizes, cultures, religions, sexualities and abilities (Preiser \& Ostroff, 2001). Quite simply the use of universal design principles furthers the spirit and intent of human rights legislation through being more appropriate, effective and efficient means to plan communities and allows PwD to participate in 
ways which are seamlessly equitable, dignified, promote independence, and are safe and affordable (Olympic Co-ordination Authority, 1999).

While most PwD strive for community participation the most important consideration is that they have the right to choose what they participate in and how they participate in it. There are many cultural activities that people still choose to undertake in a segregated environment (Smith, Austin, Kennedy, Lee, \& Hutchison, 2005). As Stebbins (2006), Smith et al. (2005) and others outline, cultural life offers a chance to engage, empower and achieve what has been described as life changing (NICAN, 2005a, 2005b). Yet, as recent research into inclusive leisure practice for disability groups suggests, the objective is a long way from being achieved (Bigby, 2008; Devine \& Parr, 2008).

The Olympic Coordination Authority successful staging of the Sydney 2000 Olympic and Paralympic Games from a logistical disability perspective were based on the underlying values of equity, independence and dignity (Darcy, 2003) and these principles are enshrined in Smith et al.'s and NICAN's (2005a) approaches to inclusive cultural life. Some studies of sport policy (Donnelly, 2008) and tourism (Miller \& Kirk, 2002; Shi, 2006; Russell Williams \& Rattray, 2005) exist but other aspects of experiences PwD within a stated human rights and legal framework of cultural life are underexplored.

Disability, human rights and the Australian system of disability discrimination law The twentieth century has been characterized by campaigns for equal rights and social justice by a number of groups including women, ethnic minorities, indigenous peoples, and gays and lesbians. The rights of PwD were not specifically mentioned in the United Nations' Universal Declaration of Human Rights (1948) and did not receive formal 
international recognition until the United Nations' Declaration on the Rights of Disabled Persons (1975). Following from this the United Nations' (1976) declared that 1981 would be the International Year of Disabled Persons (IYDP). The IYDP was seen as a watershed event for the rights of PwD in many countries. In Australia the IYDP was marked by Commonwealth (national government) initiatives, a range of state initiatives, and importantly the emergence of a disability political movement that for the first time had been able to organize around a focal point (Clear, 2000, pp. 54-55, 81). Following from the IYDP the United Nations declared that 1983-1992 was the Decade of Disabled Persons. This decade saw many initiatives by member states to address their particular disability issues.

Following this decade, the United Nations General Assembly passed a resolution The Standard Rules on the Equalization of Opportunities for Persons with Disabilities (1993). The resolution adopted a social approach to disability, calling governments to provide for the equalization of opportunities for $\mathrm{PwD}$ in all aspects of their lives. The resolution identified recreation and tourism as Target Areas. The Australian government became a signatory to the United Nations' Convention for the Rights of People with Disabilities (2006, 2008). Article 30 of the Convention specifically identifies the rights of PwD to culture, recreation and tourism. The Convention has become the international framework under which nations implement human rights for PwD. In Australia, the Disability Discrimination Act, 1992 (DDA) has been the way that the Australian Commonwealth government implements its international disability rights commitments since 1st January 1993. The implementation of the DDA will now be discussed in the Australian context. The development of disability policy in Australia has been thoroughly reviewed elsewhere (Clear, 2000; Goggin \& Newell, 2005). 


\section{Disability Discrimination Act, 1992}

The evolution of disability services and the development of anti-discrimination legislation provided a foundation for greater participation by $\mathrm{PwD}$ in the Australian community. The momentum that this built over the 1980s provided the climate to establish a dedicated human rights based approach to disability across Australia (Hastings, 1997). The DDA was the first disability specific legislation in Australia to provide protection for all Australians against disability discrimination. The premise of the DDA was that disability discrimination happens when a person with a disability is treated less fairly than someone without a disability. The key objective of the DDA is to 'to eliminate, as far as possible, discrimination against persons on the ground of disability...to ensure, as far as practicable, that persons with disabilities have the same rights to equality before the law as the rest of the community’ (Section 3). The DDA uses a similar functional loss list to define disability to that of the Australian Bureau of Statistics (ABS) (1998). However, it does make a more inclusive addition of temporal elements by stating that people cannot be discriminated against because of a disability they 'have now, had in the past, may have in the future or are believed to have'. It also importantly includes people who may have the presence of disease causing organisms in their body (HIV/AIDS and hepatitis). The Human Rights and Equal Opportunity Commission (HREOC - from 2008 known as the Australian Human Rights Commission) interpret this section of the Act with a more social approach to defining disability under access categories.

The DDA also provides protection against discrimination because a person with a disability is: Accompanied by an assistant, interpreter or reader; Accompanied by a trained animal such as a guide or hearing dog; or uses equipment or an aid, such as a hearing aid. The DDA also provides protection for the carers, friends, relatives and co- 
workers of people with a disability if they are discriminated against because of the person's disability. The DDA implicitly makes it unlawful to discriminate against PwD in the following areas of life (DDA Section 3): Employment; Education; Access to premises used by the public; Provision of goods, services and facilities; Accommodation; Buying land; Activities of clubs and associations; Sport; Administration of Commonwealth Government laws and programs.

The considerations for cultural providers are that any public area or services offered require consideration of the DDA. As a service driven industry there are particular requirements to ensure that access to goods, services and facilities and public places that make up the customer service provisions of the industry. The provisions for making these areas accessible are governed by the Building Codes of Australia (Australian Building Codes Board, 1996, 2004), the referenced Australian Standards for access and mobility (Standards Australia, 1992a, 1992b, 1992c, 1995, 2001) and the Draft Disability Standards for Access to Premises (Commonwealth Attorney General's Dept., 2008). Some changes have been easier to make than others (i.e. kerb ramps) while others will need to be staged over many years (i.e. public transport). It was not expected that access to public places would occur overnight and there were no provisions for automatically retrofitting older facilities in the DDA has. The latter is required if a major redevelopment or a change of use is proposed under environmental planning legislation.

\section{Reasonable adjustment and unjustifiable hardship}

Reasonable adjustment and unjustifiable hardship are central concepts to the interpretation of the DDA and the complaint process in determining outcomes for when discrimination has occurred. Reasonable adjustment can be any form of assistance or 
adjustment that is necessary, possible and reasonable to make to reduce or eliminate disabling environments. The philosophy of adjustments is to provide an equal opportunity for PwD to participate in community activities. While reasonable adjustment seeks to promote equitable access, unjustifiable hardship is used to protect organizations from making major changes that may have excessive costs and dire economic consequences to a person or organisation (Human Rights and Equal Opportunity Commission, 2001).

There are four main mechanisms to changing discriminatory practice under the DDA: education; complaint cases, HREOC hearings and Federal court actions; disability standards; and disability action plans. Central to the objectives of the DDA is the ongoing education of the public about disability discrimination. Three other strategies work in unison with education. Under Section 69 of the DDA people with a disability have the right of complaint when they believe they have been discriminated against. Ninety five percent of complaints brought to HREOC are dealt with through staff investigation and conciliation (Hastings, 1995, 1997). Depending on the nature of the complaint case, conciliated outcomes may take the form of: Payment of damages; Job reinstatement or job promotion; An apology; Changes in policies or practices; and/or Some other outcome.

If complaints cannot be resolved through conciliation then the people with disabilities can ask for the complaint to go to a HREOC hearing (pre-2000) or have the complaint heard by the Federal Court of Australia. The advantage of a Federal Court decision is that it is binding on the parties whereas a HREOC ruling is not (Hastings, 1995). As Thornton (2000, p.16) believes, a weakness of the complaint system is the confidentiality of the process that individualizes the outcomes rather than contributing 
towards the challenging of the social norms of discrimination through the public reporting of outcomes. Brandy v Human Rights and Equal Opportunity Commission [1995 HCA PLPR 19] determined that it was unconstitutional for HREOC to formally hear complaints and make binding decisions. Therefore, all complaints requiring an enforceable, legally binding and public decision must be heard by the Federal Court of Australia. Unfortunately, the Federal court is also a cost jurisdiction where any individual bringing a court action may not only have their own costs of representation to bear but also have costs of the other party awarded against them. Public enquiries, disability standards and disability action plans are part of strategic mechanisms to bring about organisational change. With this background, the research problem seeks to understand the rights of citizenship to cultural life as experienced by PwD under the DDA since its implementation.

\section{Empirical findings and discussion}

With this understanding of the Australian disability discrimination legislation, this section presents the findings from the analysis of the complaint cases and Federal court actions. First, information about the sample is presented including an overview of complaint cases lodged across all areas of human rights responsibilities in Australia. This is followed by a detailed description of complaint cases that fall under the rubric of cultural life. Second, a statistical analysis of the cultural life complaint cases is presented to provide an understanding of group difference across major areas of discrimination. Third, the reoccurring themes from the complaint cases are then presented together with discussions of implications for citizenship within cultural life. The themes include: general access to the built environment; role of consent authorities; hotels and motels; transport; smoke-free environments; assistance animals; 
telecommunication, inclusive information provision and interpretive services; and customer service.

\section{The Sample}

Figure 1 reinforces that disability discrimination as a proportion of complaint cases lodged by sex, race, age and administrative issues is by far the largest category making up $48 \%$ of the workload of HREOC (Human Rights and Equal Opportunity Commission, 2007).

Figure 1: Proportion of HREOC complaints cases by act

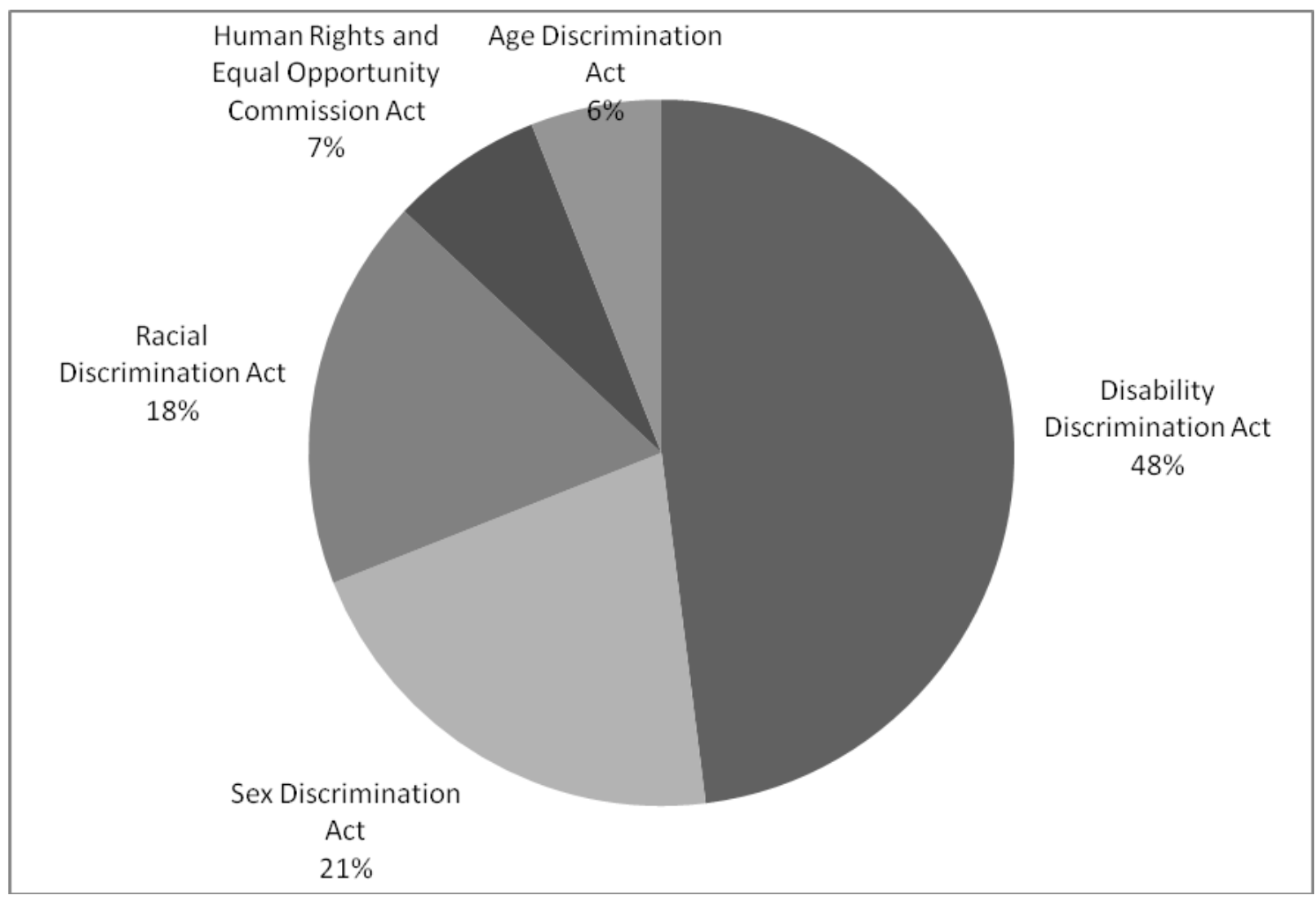

Source: HREOC 2007

Figure 2 shows the number of DDA complaint cases from 1996-2007, with approximately 7000 complaint cases lodged within that period at an average of 575 per 
year. While the numbers varied each year, approximately 35 percent of all complaints made were successfully conciliated to an outcome with the remainder being terminated due to not being deemed disability discrimination, terminated for other reasons or voluntarily withdrawn. Some of the complaints cases not conciliated may have proceeded to either HREOC inquiries (pre 2000) or Federal Court actions (post 2000 see Brandy v HREOC [1995]). The most common reason for termination of a complaint was that it was trivial or misconceived (22\%) or that there was no reasonable chance of conciliation (15\%). Of these complaint cases, just under half of each year are for employment, followed by goods/services/facilities (25\%), and access to premises (7\%) (Human Rights and Equal Opportunity Commission, 2007).

\section{Figure 2: Disability Discrimination Act - No. Of Complaint Cases}

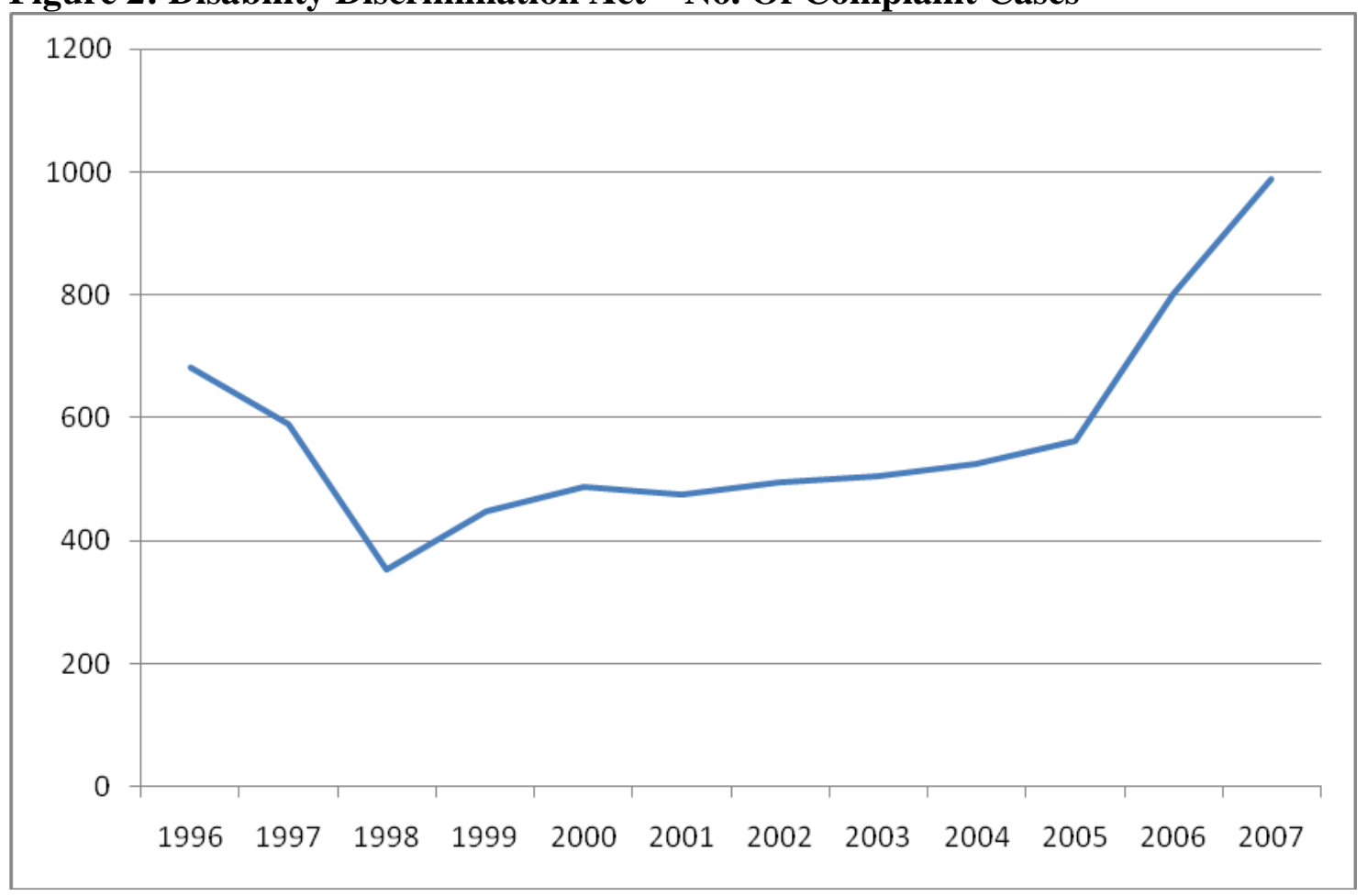

\section{Source: HREOC Annual Reports}

Some 420 complaint cases together with some 80 HREOC hearings and Federal court cases were included for the analysis. The following quantitative analysis is based on the 
complaint cases. The recurring themes of the complaint cases is supplemented with the HREOC hearings and Federal court actions (HREOC, 2005). The purpose of this paper is to examine the outcomes of those complaint cases and Federal court actions determined to be discriminatory.

\section{Quantitative findings}

As Table 1 identifies, the Chi-squared test for independence was undertaken to determine whether there is relationship between the type of discrimination encountered by gender, disability type, entity making the complaint and industry sector. There were statistically significant relationships between the types of discrimination by all but the entity making the complaint. The Pearson coefficient $(\mathrm{P})$ value is significant if less than $<.05$. The phi or Cramer's V coefficient value indicators the effect size using Cohen's (1988) criteria of small, medium or large effect taking into account the degrees of freedom. Gender was significant to the 95\% level and regarded have a small effect, where both disability and sector were significant than 99\% level and regarded to have a medium and large effect respectively.

Table 1: Chi-Square Test for Independence

\begin{tabular}{lccccc} 
Discrimination by & $\mathbf{N}$ & $\mathbf{d f}$ & $\mathbf{P}$ & Phi & Cramer's V \\
\hline Entity & 417 & 4 & .262 & .112 & .112 \\
Gender & 420 & 8 & $.045^{*}$ & .194 & .137 \\
Disability & 420 & 12 & $.000^{* *}$ & .451 & .261 \\
Sector & 415 & 4 & $.000^{* *}$ & .290 & .290 \\
\end{tabular}

Note: $*<0.05 * *<0.01$; 
In reviewing the cross tabulations further insights can be found for gender, disability and industry sector. Furthermore, women were three times as likely to experience discrimination with accommodation provision and were a third more likely to experience discrimination with goods/services/facilities. Men were a third more likely to experience discrimination with clubs/other associated bodies. While Chi-square analysis does not show causal reasons, the suggested relationship between the variables has considerable implications for the citizenship of those affected.

While in many people's minds "physical access” to buildings for people with mobility disability has a far greater awareness amongst the public, as Figure 3 demonstrates, it was still by far the area of most discrimination. This includes a series of simple access provisions such as ramps, hand rails and tactile ground surface indicators. What becomes apparent is that people with mobility disabilities are asserting their rights to access all areas and that the complexity of access to buildings increases with the considerations of all spaces within buildings and other dimensions of disability. While not collected, it would have been interesting to ascertain as to whether access to buildings were for buildings that had been recently constructed. The DDA does not include provisions for retrofitting unless a "change in use" is to occur where $50 \%$ of the floor space ratio is to be changed. These provisions are reinforced by the environmental planning legislation in most states. 


\section{Figure 3: Discrimination by Disability Type}

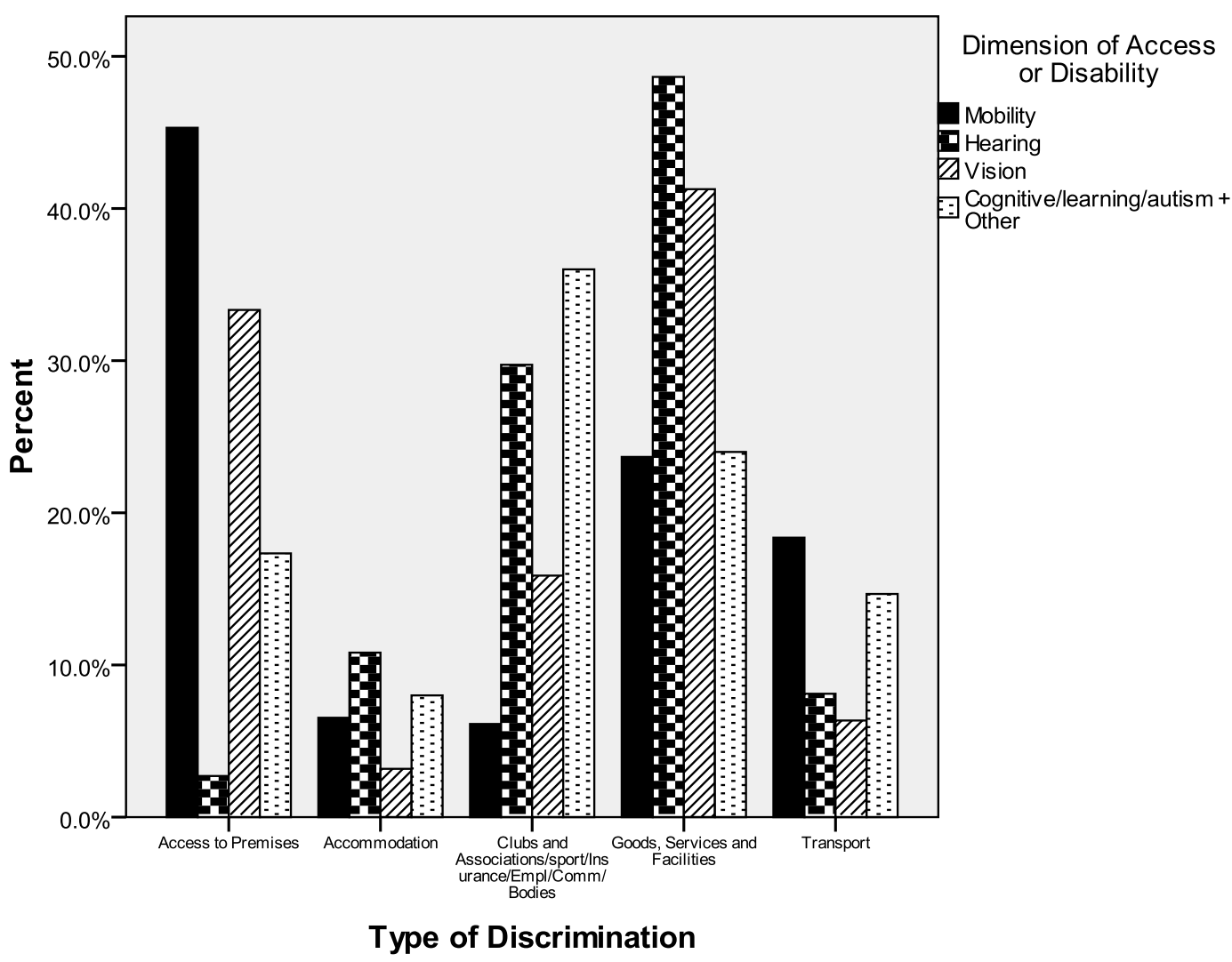

Discrimination against people seeking accommodation occurred at double the rate against commercial providers compared to government providers of accommodation. This suggests that for whatever reasons, the commercial tourism sector were not aware of the provisions of the DDA or their premises were not as accessible as those provided in the public housing sector. Figure 4 shows that the commercial sector (compared to the public sector) was more likely to have a complaint case brought against them for the provision of goods and services. This finding may be tempered as the commercial sector is the major provider of goods and services. Government was more likely to have a complaint case raised on grounds of employment and Commonwealth services. 
Figure 4: Discrimination by Sector

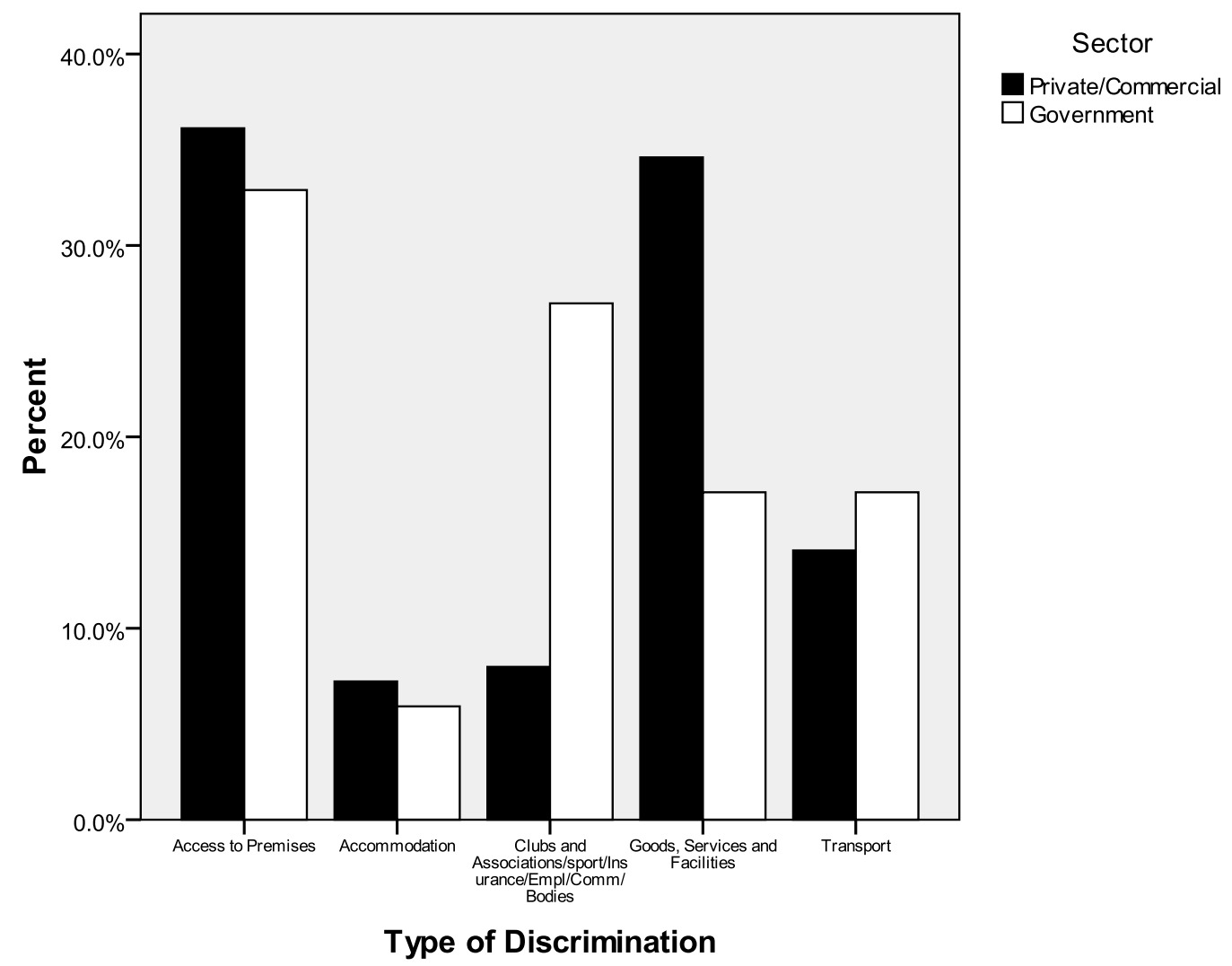

\section{Reoccurring Themes}

This section focuses on the recurrent themes in the complaint cases and Federal court actions across the areas of cultural life.

\section{General access to the built environment}

Many of these cases involved direct and obvious exclusion from premises due to the lack of basic physical access inclusions (e.g. pathways, kerb cuts, ramp, lifts, handrails etc.) incorporated into a continuous pathway. A continuous pathway is defined under the Australian Standards for access and mobility as:

An uninterrupted path of travel to or within a building providing access to all required facilities. For non-ambulatory people, this accessible path shall not incorporate any step, stairwell or turnstile, revolving door, escalator or other impediment which would prevent it being negotiated by people with a disability (Standards Australia, 2001, p. 5). 
It is these basic physical access requirements that still make up the bulk of complaint cases. For a full list of access requirements see the Australian Standards for access and mobility (Standards Australia, 1992a, 1992b, 2001, 2002). Many PwD are frustrated by the lack of accessibility of much of the built environment. The complaint cases identified shops, restaurants, attractions, sport facilities, natural areas, theatres, cinemas and other places of interest to residents and tourists alike. Apart from the previously mentioned inclusions the two most common omissions of access are parking and toilets. Accessible parking is essential given the general lack of accessibility of public transport, the extra space required to transfer from car to wheelchair or to ingress or egress from side or rear loading vehicles.

One case that demonstrated a lack of forethought by those involved was a major Sydney-based university who advertised for people spinal cord injury to become involved in research for a physical activity programme. Upon attending a session a person brought it to the attention of the program provider that there were no accessible toilets or changing rooms. The program provider's reply was "that was just the way it was”. It was only after the complaint case was brought that a conciliated outcome was reached to fast track the provision of accessible toilets and changing rooms. No other group in society would be expected to participate in the community without the use of toilets. Apart from being able to get into toilets and requiring spacious layouts, some PwD have personal care requirements were the provision of unisex toilet is essential. A number of cases highlighted people who required the assistance of an attendant. Similarly, people with vision impairments are confronted by the lack of basic physical access through the lack of provision of tactile ground surface indicators (TGSI) and audio signals (e.g. in lifts). 
A major principle that the DDA establishes is the equality of provision. One of the first cases tackling equality of access for people with mobility disabilities was Cocks $v$ the State of Queensland [1994]. It involved a recently opened Brisbane Convention and Exhibition Centre where people with mobility disabilities were required to access the building through a secondary side entrance where all other patrons entered through a front entrance that was built with stair access only. The Centre in response applied for unjustifiable hardship but this was not upheld given the status of the venue, overall costs and the estimated 315,000 people per year who would attend the facility who could not use stairs. The outcome of requiring a universal entrance has become a benchmark for provision.

The other major areas highlighted were the breakdown in the process of planning, design, construction and operations. While the Building Code of Australia and Australian Standards have had access requirements since the late 1970s, many of the professionals involved in the construction process have largely remained ignorant of these requirements. One of the landmark cases to challenge the planning processes' understanding of accessibility was Cooper \& Ors v Holiday Coast Cinema Centres Pty Ltd [1997 HREOCA 32]. Cooper Cooper challenged the provision of stair only access by a company that deliberately did not include lift access to a new cinema in Coffs Harbour. They were found to have discriminated against users who could not use stairs and were ordered to remedy the situation. The company made an application for unjustifiable hardship but this was rejected based on the overall cost of the development, the company's financial position and yearly turnover. Coffs Harbour cinema was made accessible through the provision of the lift, and it currently operates profitably, serving all members of the community. 
Role of consent authorities

In an extension of Cooper \& Ors v Holiday Coast Cinema Centres Pty Ltd [1997 HREOCA 32], Cooper, President North Coast D.I.A.L. Inc. V Coffs Harbour City Council [2000] sought remedy for the consent authority who approved the cinema development application under the Environmental Planning and Assessment Act, 1979 (NSW). The result of the case was that consent authorities have a responsibility to ensure that developments not only comply with the BCA, referenced Australian Standards but also the spirit and intent of the DDA. This case also meant that property owners could no longer feel confident without their development complying with the spirit and intent of the DDA. The Disability Discrimination Commissioner (Ozdowski, 2001) reinforced this finding through his interpretation of the DDA supported local government's liability for permitting inaccessible development. It was based on Pruszinski Architects v. the City of Adelaide (No. 84 of 2001) and the case of providing access to a swimming pool in a new Hotel complex. While the BCA does not specifically address access to swimming pools it is covered by the DDA. As such, any regulatory authority or owner/operator would be liable to a complaint under the DDA if someone believed they were discriminated against by not being able to access the swimming pool. The provision for ‘unjustifiable hardship' would require interpretation by the Courts. The applicant sought exclusion by contending that the BCA does not specifically address swimming pool access. Yet under the DDA access is not just the provisions of the BCA but is far broader sweeping in its spirit and intent, and hence, discrimination on the basis of disability. In making these comments Ozdowski (2001) reinforced the findings of Cooper and others v. Coffs Harbour Cinemas, and Cooper v. Coffs Harbour Council, for both the proponent and the consent authority. Another 
outcome of this finding was placing professionals involved in construction process as being professionally liable for their lack of access consideration.

\section{Communicating the accessibility of Hotels and Motels}

Closely linked to the above themes is the accessibility of the accommodation sector. There were numerous reported complaints involving tourism accommodations that involved a range of access and communication issues. This is not surprising given the importance of accessible accommodation to being able to travel away from home for cultural related activities. Quite simply, if a person cannot find accessible accommodation they are not able to participate in the activity they wished to away from their place of residence. Further, if they thought they had booked an accessible accommodation and then arrived at the destination to find out that the accommodation is not accessible it could be a devastating experience.

The major areas where complaint cases were brought included price differentiation where accessible rooms cost more than standard rooms, accessible features that were not compliant to the building codes, poor wayfinding that led to inconvenience and accidents, segregated entrances and lack of access to all areas of the premises. In the worst case a newly constructed was so poorly designed that it was impractical for people to stay overnight. However, the most common complaint had to do with the information provision. An analysis of these complaint cases suggests that the accessible accommodation information systems require accurate, detailed and illustrated information about the accommodation. Recent research in Australia and overseas has been addressing these shortcomings in accessible at accommodation information provision (Darcy, 2007b; Europe for All, 2007). Operational issues formed part of other 
complaints and hearings that were based at hotels but are discussed as part of customer service issues.

\section{Transport as a facilitator of cultural experience}

Transport is a major facilitator of people’s cultural experiences. Transport has been an area that a number of alternative strategies have been used outside of the complaint system through Standards and public inquiries. However, the complaints that had the largest ongoing impact were public transport based. Three separate but simultaneous complaint actions were undertaken against government bus fleet purchases in NSW, SA and WA. These were about proposed the new bus purchases. An interim injunction was granted stopping the purchase and undertakings were then committed to the purchase of wheelchair accessible buses. Arguably these complaints have had the impact of providing the impetus for the Disability Standard for Accessible Public Transport (Commonwealth Attorney General's Dept., 2001a, 2001b) and the foundation for a strategic approach to accessible public transport systems throughout Australia. While this has been successful with government bus services it has been less successful with the adoption of wheelchair accessible buses by private coach operators. For example, it has been estimated that 45 percent of the government bus fleet is accessible but only 10 percent of private bus services are accessible (Allen Consulting Group, 2008).

Many other complaint cases highlighted a range of public transport issues and transport involving cultural services. All forms of transportation were identified including rental vehicles, coach, rail and ships. Most major hire car firms now provide cars fitted with hand controls on request to PwD. Access to these facilities can be problematic in rural centres. Access to country train services has been problematic because much of the infrastructure was built during the last century and a number of complaints relate to this 
issue. This is a serious barrier to travel for $\mathrm{PwD}$ wishing to get to rural areas of Australia. However, other complaints have brought attention to the rail carriages themselves for: lack of accessibility of long haul travel carriages; inappropriate provision of wheelchair space; lack of accessible sleeping quarters in new carriages; and provision of accessible toilets only in the $1^{\text {st }}$ class cabin area.

These problems have been compounded where buses have been contracted for service on lower capacity routes instead of maintaining rail services. This situation has occurred in NSW on Countrylink rail services. Many of the long-term bus contracts did not specify that accessible buses had to be used.

This situation also extended to private tour companies who specialize in day trips by coach and ship. In Australia's largest destination, Sydney, people with mobility disabilities are unable to book accessible day trips on any of the major day tour operators (Darcy et al., 2008). This means that destinations like the Blue Mountains National Park are inaccessible as the public transport system is also inaccessible to this area. People with mobility disabilities are restricted hiring accessible vehicles themselves and undertaking segregated trips. This means they are excluded from the social interaction of the organized tours, benefiting from the expertise of the organized tour operators and contributing to these companies’ profits.

A great deal of air travel is done for cultural purposes. Air travel complaints have risen significantly over the last four years. The seriousness of the situation led the Public Interest Advocacy Centre (2007) producing a major research report on the associated issues from over 100 disaffected parties. Airlines have also been the main applicant for exemptions under the DDA (Human Rights and Equal Opportunity Commission, 2008). 
The options of travelling to country and regional areas for people with higher support needs were further restricted through McLean v. Airlines of Tasmania Pty Ltd [1996 HREOC 77]. McLean sought to maintain his independence in regional air travel by not having to provide his own support person while travelling on Airlines of Tasmania. The Commissioner found that because McLean was a person with a high support level disability that he would be required to provide his own support person due to safety and resource reasons. It was also found that it would be an unjustifiable hardship for the Airline to provide such a person. This finding was also reinforced where it was found not to be unlawful to require a woman with epilepsy to be accompanied on a long international flight. In other cases there have been procedural issues with booking flights with extra equipment (oxygen or sealed wheelchair batteries) based on the Air Navigation Act and have led to complaint cases. The resolution of these cases has seen changes in policy and booking procedures to avoid undue delays or refusal of entry onto flights.

This has been exacerbated by the Virgin Blue introduction of the 'independent travel criteria', which requires a person who cannot perform certain tasks to travel with a carer or be excluded from their flight (Virgin Blue, 2007). What is significant about this action by Virgin Blue is that the independence of the individual can be judged arbitrarily by company personnel without any experience of disability. Further, Virgin’s European air operations do not apply the same tests (Darcy, 2007a). A Federal court action is currently being contested over this issue with no resolution at the time of writing.

A significant number of complaint cases highlight the vagaries that people with disabilities face in dealing with individuals within the transport sector. Adams $v$ Arizona 
Bay Pty. Ltd., Charlie Habib and Bunge Pty. Ltd. [1996] provides a confronting example of the problems that PwD using paratransit systems face on a daily basis. This case also highlighted the vulnerability of PwD who were reliant on a single transport provider. This is encapsulated in the following quote from the proceedings of the case,

'I'm doing you fucking cripples a favour picking you up anyway'. Mr. Adams went on to allege that he asked Mr. Habib a few times to stop the car but Mr. Habib drew alongside Mr. Adam's house and said 'this is my fucking company and I make the fucking rules'. Mr. Adams further alleged that he said then that he held a M40 card and would call Vicroads to check his rights and change to another taxi service. At this Mr. Habib said 'you do that, I'll make your fucking life suffer. No one will be able to help you'.

The general transport issues and taxis specifically have been fully documented (Human Rights and Equal Opportunity Commission, 2002a; Wheelchair Accessible Taxi TaskForce, 2004).

\section{Smoke free environments and other sensitivities}

Another area of reoccurring issues have arisen over the last decade involving smokefree environments and environments free of chemicals that affect the sensitivities. While smoking bans have become standard across most Western nations, there are significant numbers of individuals who have respiratory and other sensitivities. One of the foundation cases to test this was Francey and Meeuwissen v Hilton Hotels of Australia Pty Ltd [1997]. Hilton Hotels are a global chain and most hotels have a range of restaurants and bars. Francey and Meeuwissen were attending Julianna's Nightclub in the Sydney Hilton. After a stay of about half to three-quarters of an hour they left the nightclub due to Meeuwissen being seriously affected by environmental tobacco smoke. Discrimination was alleged on the grounds that ground of Ms Meeuwissen's disability. Meeuwissen had cystic fibrosis and had a double lung transplant in 1994, and while her 
new lungs are free of cystic fibrosis they had asthmatic tendencies. The affects of environmental tobacco smoke are serious as evidenced in the proceedings of the case:

"I started to wheeze and produce mucus. This doesn't happen these days unless there is environmental tobacco smoke. .. I felt pain and discomfort. .. When I started struggling to breathe I looked around and saw some women smoking. I went to the women's toilets fairly quickly .. because I hoped that it would be a safer place. I was feeling pretty distressed physically.”

The Commissioner found that Francey and Meeuwissen had been discriminated against and that a finding of unjustifiable hardship could not be sustained with compensation being paid to both parties. Concurrently and subsequently, a number of other complaints were raised about environmental tobacco smoke. This has led to the Melbourne Cricket ground establishing smoke free areas and facilities for asthmatics and a shopping centre management establishing a total smoke free centre based on the evidence presented in Francey and Meeuwissen v Hilton Hotels of Australia Pty Ltd [1997]. Another conciliation case identified that the installation of equipment for and designation of smoke free areas needs to be both used, maintained and policed as it was found that a club who had smoke removal systems and smoke free areas had not done so. This area is an excellent example of dynamic considerations of disability considerations where community standards are continually changing. Most pubs and clubs in Australia have limited areas for smoking as of 2008. While no cases have been raised about chemical sensitivities, a number of the tourist accommodation now offer rooms that provide chemical free environments (e.g. Listers, Mollymook NSW http://www.stayz.com.au/53289 ).

\section{Assistance Animals}

In an area of ongoing complaint is that of the requirement to allow a person with an assistance animal access to premises, and access to goods, services and facilities. An early public inquiry into discrimination in this area was Jennings $v$ Lee [1996] where 
Jennings was denied access into a restaurant because of her seeing-eye dog. Many similar complaint cases have been heard over the ensuing years involving taxi services, restaurants, clubs/pubs/bars and public transport (NSW Anti-Discrimination Board, 2001b). Another case involved a tour operator who refused to allow a man who was blind be accompanied by his guide dog. The operator believed that the tour and mini bus was not an appropriate venue because of the lack of space and cramped conditions. The complaint was settled without admission of liability when the operator apologized, agreed to a change of policy to permit guide dogs in future and paid compensation.

These cases have become more complicated over the years as impairment groups other than blind people started to use assistance animals as companion and therapy animals. For example, Brown V Birss Nominees Pty Ltd [1997] is a HREOC hearing where Brown was denied accommodation at a caravan park as he was a deaf person who had a hearing dog. The caravan park owner had a rule that no animals were allowed in the caravan park but was unaware that this could not extend to assistance animals. The impact of this type of incident should not be under estimated for as was stated in this case, 'Mr Brown gave evidence that he was most apprehensive about further travel as a result of these events, and that since September 1994 he has only travelled once' (Brown V Birss Nominees Pty Ltd [1997]).

Another case involved the refusal of access to public transport of a man with a disability with his 'therapy dog'. The complaint further alleged harassment by other travellers and being scrutinised more closely by public transport staff than other passengers did. The remedy was for a letter provided by the public transport provider that explained that his dog was able to travel with him on transport. The public transport provider also 
reviewed their policy on companion and therapy animals accompanying passengers (NSW Anti-Discrimination Board, 2001b).

Telecommunications, alternative information provision and interpretive services

While not directly related to cultural life, Scott v Telstra Corporation; DPI(A) and Australian Association of the Deaf v Telstra Corporation [1997] is an excellent example of a case that has direct implications across the industry. Scott sought remedy from Telstra (Australia's major telecommunication provider) for not providing telephone typewriters (TTYs) for deaf subscribers. He sought the provision of TTYs as fair and equal treatment for deaf subscribers as Telstra provided phones to hearing subscribers. The finding had implications for all service providers to have TTYs to accept inquiries from potential deaf customers. Similarly, Maguire $v$ SOCOG (Ticket book) [1999] and Maguire v SOCOG (Internet) [2000] established that information provided in hard copy and corporation websites must be accessible to people with vision disabilities. This has major implications for the cultural industry as the Web is often the preferred source of information by consumers. Website accessibility is not a difficult task once the principles for W3C international protocols are understood (Human Rights and Equal Opportunity Commission, 2002b; Shi, 2006; R. Williams, Rattray, \& Grimes, 2006) .

These issues must also be considered by the private sector, government and not for profits with their general information provision should incorporate alternative formats such as Braille, audio tape and computer disk. Information kiosks that use visual interfaces are particularly disabling for this group. Similarly, access to ATMs has a range of access issues for people with vision impairments and people with mobility disabilities where design must incorporate physical and communication dimensions of 
access. The physical design of public phones has been an ongoing issue for people with mobility disabilities. Hence, organisational communication requires a strategy to communicate with all constituent stakeholders.

\section{Customer service}

Customer service issues are central to the industry and have been highlighted in numerous complaint cases. In some instances the discrimination experience by PwD is direct and unconscionable such as the case of a man with burn scars who had been told by staff in a shop that he was 'scaring other customers away'. In other cases it involves less favourable treatment where $\mathrm{PwD}$ are not treated in the same manner as others. One such complaint case was of a wheelchair user where staff demanded they move from where they were sitting in a prime location and provided them with less favourable treatment because of the disability. The complaint was settled without admission of liability when the respondent agreed to pay a sum of money, to write a letter of apology to each complainant and to submit an article on disability discrimination to the relevant industry journal.

In White v Crown Casinos Ltd. [1995], White had an Acquired Brain Injury (ABI) that affected his gait and speech and makes him appear intoxicated when he was not. On two occasions in attempting to enter Crown Casino he had difficulties entering the Casino. The Commissioner held that there was no direct discrimination because if a person without ABI had manifested the same symptoms as Mr White the Casino would have reacted in the same manner. This meant that no less favourable treatment would have been afforded to a PwD in similar circumstances due to the Casino having to comply with the Liquor Act and it had done so in a reasonable manner. Similarly, a complaint case of a woman with a speech impediment believed that she had been refused service 
at a club because her disability made her appear intoxicated. In her case even after she produced a doctor's letter explaining the situation and the service was still refused. In this case conciliation led to the club apologizing and arranged for provision and acceptance of a card authenticating the woman's disability. These cases highlight the need for disability awareness training for customer service staff to recognize the inherent behaviour of impairment groups.

A number of complaints provide an insight into the requirements for an equality of experience. The first involves a guided tour experience where two deaf people who were to attend an outdoor recreation adventure experience and indicated that they required Auslan (Australian Sign Language) interpreting or a printed copy of the commentary provided by the guide on the experience. This was not provided and an introductory video was not captioned. The tour company now provides these inclusions and they are trialling a hearing loop on the tours. Similarly, a deaf person made approaches to a conference organizer about requiring Auslan interpreters but was told this could not be provided. However, after the intervention of the NSW Antidiscrimination Commission interpreters were organized for the duration of the conference (NSW Anti-Discrimination Board, 2001a). People with high support needs sometimes require the assistance of attendants. A number of cases have highlighted the discrimination of charging for the attendant to assist the person at conferences or events (Gregory, 1999). It has become standard practice by many organisations to provide a two-for-one entry to conferences, theme parks and events where people with disabilities are assisted by attendants. The Victorian government introduced a Companion Card to formalise this approach and provide a series of other discounts to the 'disability market'. The program has now been adopted nationally (Companion card, 2008). 


\section{Implications for inclusive cultural practice}

What insights do the proceeding complaint cases and Federal court actions have into inclusive cultural industry practice towards PwD? To conclude, there are four major areas for consideration: understanding group disability needs; maintaining an individual focus on customer service; systemic issues with the DDA; and the dynamic nature of disability within society.

The major disability groups represented in the complaints cases, hearings and Court cases were people with mobility impairments, vision impairments, hearing impairments, respiratory conditions and people whose speech or movement was affected by their impairment. With respect to including PwD within cultural life, the same principles apply to the cultural industries as they do for other industries. There was not a single conciliated complaint case whose circumstances could not have been foreseen under the DDA. The inclusive provisions for the various dimensions of access have been well tested but not well implemented. The paper did not investigate the reasons why these situations arose, however, the outcomes of the cases provide significant direction to the industry: get the built environment right from the beginning; engage professionals who understand the requirements of accessibility; treat customers as you would want members of the family treated; staff require disability awareness training as much as they require training on occupational health and safety issues; communicate access provisions to consumers in a detailed manner; and communication requires accessible alternative formats.

It may not be surprising that people with intellectual and mental health are underrepresented generally within the complaint process. However, it should be noted that mental health related issues are the major area of complaint for employment related 
issues. The experiences of individuals within cultural life are critical to this because of the complex interplay between impairment, disability and environment (Aitchison, 2003; Packer et al., 2007; Shakespeare \& Watson, 2001; Thomas, 2004). While there can be significant understanding developed from the disability group experiences, significant respect must be paid to the circumstances of the individual and how they interact with their environment. This provides an inherent complexity to the cultural industry interaction with people with disabilities but at the same time has the basic customer service principle the importance of engaging with each individual as an individual.

The legal provisions of the DDA have given $\mathrm{PwD}$ a voice to redress individual injustices. Yet, this system is not without problems as the onus is on the individual to make the complaint, complaints are confidential, and hence, to not have a common law basis (Handley, 2001; Jones \& Basser Marks, 1999; Thornton, 2000). Similar cases may already be in conciliation at the time the complaint case is made or similar complaint cases may have already been heard at due to the lack of common law precedent of complaint cases, hence the outcomes of these cases have little impact across the cultural industries or social practice (Handley, 2001; Jones \& Basser Marks, 1999; Thornton, 2000). This is different to the ADA, which has common law precedent and is rights based legislation where industry sectors are put on notice to perform to criteria based standard within set timeframes. The above cases highlight ongoing discrimination against PwD that have been dealt with in many similar circumstances by HREOC previously. Given the trend of increasing number of complaint cases, there are significant issues for the resourcing of the process and the general inefficiency of outcomes. As some will have noted in reading the results, there has been a significant fall in the number of Federal Court actions since the 2000 implementation of Brandy $v$ 
HREOC [1995 HCA PLPR 19] ruling that forced HREOC hearings to become matters of the Federal Court and, hence, a cost jurisdiction. Quite simply in the area of cultural life, people with disabilities were not willing to take the risk of a Federal Court action as costs could be awarded against them even if they won the case.

Government and the cultural industries in Australia have a legal responsibility under the DDA and other State based complementary legislation not to discriminate against people on the ground of disability. This responsibility was reinforced by the UN Convention on the Rights of People with Disabilities (2006; 2008). However, this review of the actions brought before the DDA shows that PwD are discriminated against on a daily basis in their cultural lives particularly in relation to access to premises; access to goods, services and facilities; and employment. The complaints cases and Federal Court actions signify an industry who on the whole has not engaged with disability as it has with other groups (gender, race, age and sexuality) designated under the human rights umbrella and as evidenced by the number of complaints brought each year.

\section{Conclusion}

Australia has many fine examples of inclusive cultural practices. Yet, as this paper has presented there are many cases of disability discrimination in cultural life and, as evidenced by the increasing number of complaint cases each year, this is an ongoing concern. Whether this is due to ignorance, unwillingness or lack of experience to deal with the issues is yet to be determined. If you ask people with long term disability whether there has been an improvement in the overall accessibility of their citizenship since the introduction of the DDA we have no doubt that the answer would be yes. However, this does not mean that the 'the job is done' as there are evolving expectations 
of accessibility across disability groups as new knowledge is discovered, technologies

invented and expectations heightened. The DDA was written as a dynamic piece of

legislation whose spirit and intent is to evolve to facilitate an increasingly accessible

citizenship so that people with disabilities are treated equally before the law.

\section{References}

Aitchison, C. (2003). From leisure and disability to disability leisure: developing data, definitions and discourses. Disability \& Society, 18(7), 955-969.

Allen Consulting Group. (2008). Review of the Disability Standards for Accessible Public Transport. Allen Consulting Group for the Minister for Infrastructure, Transport, Regional Development and Local Government in consultation with the Attorney-General Retrieved 23 Feb 2008, from http://www.ddatransportreview.com.au/downloads/ACGTransportReviewPartA.rtf

Australian Building Codes Board. (1996). Building Code of Australia. Canberra: CCH Australia.

Australian Building Codes Board. (2004). Draft Disability Standards for Access to Premises. Canberra: Australian Building Codes Board

Australian Bureau of Statistics. (1998). Disability Ageing and Carers Summary Of Findings (Cat No. 4430.0). Canberra: Australian Bureau of Statistics.

Barnes, C., Mercer, G., \& Shakespeare, T. (1999). Culture, leisure and the media. In C. Barnes, G. Mercer \& T. Shakespeare (Eds.), Exploring disability: a sociological introduction (pp. 182-210). Malden, Mass: Polity Press.

Bigby, C. (2008). Known well by no-one: Trends in the informal social networks of middle-aged and older people with intellectual disability five years after moving to the community. Journal of Intellectual \& Developmental Disability, 33(2), 148 - 157.

Center for Universal Design. (2009). Universal Design Principles. Retrieved 20 May, 2009, from http://www.design.ncsu.edu/cud/about_ud/about_ud.htm

Clear, M. (2000). Promises Promises: Disability and Terms of Inclusion. Sydney: Federation Press.

Commonwealth Attorney General's Dept. (2001a). Disability Standards for Accessible Public Transport. Canberra: AGPS.

Commonwealth Attorney General's Dept. (2001b). Disability Standards for Accessible Public Transport Guidelines. Canberra: AGPS.

Commonwealth Attorney General's Dept. (2008). Disability (Access to Premises - Buildings) Standards. Retrieved 2 December, 2008, from http://www.ag.gov.au/premisesstandards

Companion card. (2008). Companion card. Retrieved 2 December 2008, from http://www.companioncard.org.au/cc/CCPortal/portal_index.htm

Cooper, R. A., Quatrano, L. A., Axelson, P. W., Harlan, W., Stineman, M., Franklin, B., et al. (1999). Research on physical activity and health among people with disabilities: A consensus statement. Journal of rehabilitation research and development, 36(2), 142-154.

Cozzillio, M. J., \& Hayman, R. L. (2005). Sports and inequality. Durham, N.C.: Carolina Academic Press.

Darcy, S. (2001). People with physical disabilities and leisure. In I. Patterson \& T. Taylor (Eds.), Celebrating Inclusion and Diversity in Leisure (pp. 59-80). Melbourne: HM Leisure Planning Pty Ltd.

Darcy, S. (2002). Marginalised participation: Physical disability, high support needs and tourism. Journal of Hospitality and Tourism Management, 9(1), 61-72.

Darcy, S. (2003). The politics of disability and access: the Sydney 2000 Games experience. Disability \& Society, 18(6), 737-757.

Darcy, S. (2007a, 19-23 June). Flying With Impairments: Improving Airline Practices By Understanding The Experiences Of People With Disabilities. Paper presented at the Beating the Odds with Tourism Research!, Las Vegas, Nevada.

Darcy, S. (2007b, 11-14 February). A methodology for assessing class three accessible accommodation information provision. Paper presented at the Tourism - Past Achievements, Future Challenges, Manly Pacific Novotel, Manly - Sydney Australia.

Darcy, S., Cameron, B., Dwyer, L., Taylor, T., Wong, E., \& Thomson, A. (2008). Technical Report 90064: Visitor accessibility in urban centres. Sustainable Tourism Cooperative Research Centre, 
Gold Coast. $\quad$ Retrieved July 2007, from

http://www.crctourism.com.au/BookShop/BookDetail.aspx?d=626

Devas, M. (2003). Support and Access in Sports and Leisure Provision. Disability \& Society, 18(2), 231 245.

Devine, M. A., \& Parr, M. G. (2008). 'Come on in, but not too Far': Social Capital in an Inclusive Leisure Setting. Leisure Sciences, 30(5), 391 - 408.

Donnelly, P. (2008). Sport and human rights. Sport in Society, 11(4), 381 - 394.

Europe for All. (2007). Tourism Providers reports on The Europe for all Self-Assessment Questionnaire: For owners/managers of Hotels and Self-Catering Establishments \& The Europe for all Photo and Measurement Guide. Europe for All - Better information for discerning travellers, EU. from http://www.europeforall.com/tourismProviders.seam?conversationPropagation=end\&conversatio $\underline{\mathrm{nId}=162076}$

Glaser, B. G., \& Strauss, A. L. (1967). The discovery of grounded theory: strategies for qualitative research. Chicago: Aldine Pub. Co.

Gleeson, B. (1999). Geographies of Disability. London: Routledge.

Goggin, G., \& Newell, C. (2005). Disability In Australia: Exposing a Social Apartheid. Sydney: University of New South Wales Press.

Gregory, P. (1999, 4 August). Games ticket win to quadriplegic. The Age, p. 3,

Handley, P. (2001). 'Caught Between a Rock and a Hard Place': Anti-discrimination legislation in the liberal state and the fate of the Australian Disability Discrimination Act. Australian Journal of Political Science, 36(3), 515-528.

Hastings, E. (1995). Clarification of High Court decision about the enforcement of HREOC determinations. Sydney: HREOC

Hastings, E. (1997). FounDDAtions: Reflections on the first five years of the Disability Discrimination Act in Australia. Sydney: Human Rights and Equal Opportunity Commission.

Henderson, K. A., Bedini, L. A., Hecht, L., \& Schuler, R. (1995). Women with physical disabilities and the negotiation of leisure constraints. Leisure Studies, 14(1), 17 - 31.

HREOC. (2005). Five Years On: An update on the complaint handling work of the Human Rights and Equal Opportunity Commission (2005). HREOC, Sydney.

Human Rights and Equal Opportunity Commission. (2001, 1 December 2001). Frequently asked questions: Employment. Retrieved 2 December, 2001, from www.hreoc.gov.au/disability_rights/faq/Employment/employment_contents.html

Human Rights and Equal Opportunity Commission. (2002a). Report: Inquiry into the NSW wheelchair $\begin{array}{llll}\text { accessible } \quad \text { taxi } & \text { service. } & \text { from }\end{array}$ www.hreoc.gov.au/disability_rights/inquiries/taxi/direction.htm

Human Rights and Equal Opportunity Commission. (2002b). World Wide Web Access: Disability Discrimination Act Advisory Notes. 3.1. Retrieved 5 January, 2007, from http://www.hreoc.gov.au/disability_rights/standards/www_3/www_3.html

Human Rights and Equal Opportunity Commission. (2007). Annual Report. Sydney: Human Rights and Equal Opportunity Commission

Human Rights and Equal Opportunity Commission. (2008). Exemptions. Retrieved January, 2002, from http://www.hreoc.gov.au/disability_rights/exemptions/exemptions.html

Hutchison, P. (1997, 10-12 October). Citizenship - Setting the Scene (Keynote Address). Paper presented at the Citizenship...beyond Disability Conference, Brisbane.

Hylton, K. (2005). 'Race', sport and leisure: lessons from critical race theory. Leisure Studies, 24(1), 81 98.

Jones, M., \& Basser Marks, L. A. (1999). Disability rights and law in Australia. In M. Jones \& L. A. Basser Marks (Eds.), Disability, Divers-ability and Legal Change (pp. 189-208). Great Britain: Kluwer Law International.

Kitchin, R. (2000). The Researched Opinions on Research: disabled people and disability research. Disability \& Society, 15(1), 25-47.

Lockwood, R., \& Lockwood, A. (Eds.). (1999). Recreation and Disability in Australia (1st ed.). Perth, WA: DUIT Multimedia.

Meekosha, H. (2006). What the Hell are You? An Intercategorical Analysis of Race, Ethnicity, Gender and Disability in the Australian Body Politic. Scandinavian Journal of Disability Research, 8(2), 161 - 176.

Meekosha, H., \& Dowse, L. (1997). Enabling Citizenship: Gender, disability and citizenship in Australia. Feminist Review, 57(Autumn), 49-72.

Meekosha, H., \& Dowse, L. (2001, November 13-16). Disability Policies and Programs in Australia. Paper presented at the International Seminar on Social Welfare in Asia and The Pacific, Tokyo. 
Miller, G. A., \& Kirk, E. (2002). The Disability Discrimination Act: Time for the stick? Journal of Sustainable Tourism, 10(1), 82-88.

NICAN. (2005a). NICAN's 10 Step Guide Line Checklist. NICAN, Canberra. from http://www.nican.com.au/docs/pdf/recreation-guidelines.pdf

NICAN. (2005b). NICAN's National Recreation Guidelines. NICAN, Canberra. from http://www.nican.com.au/docs/pdf/recreation-guidelines.pdf

NSW Anti-Discrimination Board. (2001a, November). Deaf access to conference. EQUALtime, 50, 11.

NSW Anti-Discrimination Board. (2001b, November). Therapy dog and public transport. EQUALtime, $50,11$.

Oliver, M. (1996). Understanding Disability: From Theory to Practice. Basingstoke, Houndmills: Macmillan.

Olympic Co-ordination Authority. (1999). Access Guidelines (3rd ed.). Sydney: Olympic Co-ordination Authority.

Ozdowski, S. D. (2001). Local Government Liability for Permitting Inaccessible Development. Retrieved 18 July, 2001, from www.HumanRights.gov.au/disability_rights/buildings/permit.htm

Packer, T. L., McKercher, B., \& Yau, M. (2007). Understanding the complex interplay between tourism, disability and environmental contexts. Disability \& Rehabilitation, 29(4), 281-292.

Patterson, I., \& Lobo, F. (2000). Developing a meaningful identity for people with disabilities through serious leisure activities. World leisure journal, 42(2), 41-51.

Preiser, W. F. E., \& Ostroff, E. (2001). Universal Design Handbook. New York: McGraw-Hill.

Priestley, M. (1998). Constructions and creations: Idealism, materialism and disability Theory. Disability \& Society, 13(1), 75-94.

Public Interest Advocacy Centre. (2007). Flight Closed: Report on the experiences of People with Disabilities in Domestic Airline Travel in Australia. Sydney: Public Interest Advocacy Centre

Rimmer, J. H., Rubin, S. S., \& Braddock, D. (2000). Barriers to exercise in African American women with physical disabilities. Archives of physical medicine and rehabilitation, 81(2), 182-188.

Shakespeare, T., \& Watson, N. (2001). The social model of disability: An outdated ideology? In S. N. Barnartt \& B. Mandell Altman (Eds.), Exploring Theories and Expanding Methodologies (Vol. 2, pp. 9-28). Stamford: JAI Press.

Shaw, S. M., \& Dawson, D. (2001). Purposive Leisure: Examining Parental Discourses on Family Activities. Leisure Sciences, 23(4), 217 - 231.

Shi, Y. (2006). The accessibility of Queensland visitor information centres' websites. Tourism Management, 27(5), 829-841.

Smears, L. (1996). Researching disability: a response to Karla Henderson, Leandra Bedini, Lynn Hecht and Rosemary Schuler. Leisure Studies, 15(1), 79 - 81.

Smith, R., Austin, D. R., Kennedy, D. W., Lee, Y., \& Hutchison, P. (2005). Inclusive and Special Recreation: Opportunities for persons with disabilities (5th ed.). New York, NY: McGraw Hill.

Standards Australia. (1992a). AS 1428.2 - Design for access and mobility - Enhanced and additional requirements - Buildings and facilities ([Rev. ] ed.). North Sydney, NSW: Standards Australia.

Standards Australia. (1992b). AS 1428.3 Design for access and mobility - Requirements for children and adolescents with physical disabilities North Sydney, NSW: Standards Australia.

Standards Australia. (1992c). AS 1428.4 - 1993 Design for access and mobility. Tactile ground surface indicators for the orientation of people with vision impairment. North Sydney, NSW: Standards Australia.

Standards Australia. (1995). AS 4299 - 1995 Adaptable housing. Homebush, NSW: Standards Australia.

Standards Australia. (2001). AS 1428.1 Design for access and mobility - General requirements for access - New building work. Homebush, NSW: Standards Australia.

Standards Australia. (2002). AS/NZS 1428.4 - Design for access and mobility - Tactile indicators North Sydney, NSW: Standards Australia.

Stebbins, R. A. (2000). Serious leisure for people with disabilities. In A. Sivan \& H. Ruskin (Eds.), Leisure education, community development and populations with special needs. (pp. 101-108). Wallingford, UK: CABI Publishing.

Stebbins, R. A. (2006). Serious Leisure: A Perspective for Our Time: Transaction Pub.

Thomas, C. (2004). Disability and impairment. In J. Swain, S. French, C. Barnes \& C. Thomas (Eds.), Disabling barriers-Enabling environments (pp. 21-28). London: SAGE.

Thornton, M. (2000). Neo-liberalism, discrimination and the politics of resentment. In M. Jones \& L. A. B. Marks (Eds.), Explorations on law and disability in Australia (pp. 8-27). Leichhardt, NSW: Federation Press.

Tiddy, J. (2001). It's Just Not Fair: Overcoming discrimination in Australia. Sydney: ABC Books.

United Nations. (1948). Universal Declaration of Human Rights. Geneva. www.un.org/Overview/rights.html: United Nations. 
United Nations. (1975). Declaration on the rights of disabled persons. Geneva. www.unhchr.ch/html/menu3/b/72.htm: United Nations.

United Nations. (1976). The International Year of Disabled Persons 1981 (General Assembly resolution 31/123). Geneva. www.un.org/esa/socdev/enable/disiydp.htm: United Nations.

United Nations. (1993). Standard Rules on the Equalization of Opportunities for Persons with Disabilities (General Assembly resolution 48/96). Geneva: United Nations.

United Nations. (2006). Convention on the Rights of Persons with Disabilities. New York http://www.un.org/esa/socdev/enable/rights/convtexte.htm: United Nations General Assembly A/61/611 - 6 December 2006.

United Nations. (2008, 3 May). Landmark UN treaty on rights of persons with disabilities enters into force. Retrieved 12 May, 2008, from http://www.un.org/esa/socdev/enable/rights/convtexte.htm http://www.un.org/apps/news/story.asp?NewsID=26554\&Cr=disab\&Cr1=

Virgin Blue. (2007). Independent travel criteria. Retrieved 2 May, 2008, from http://www.virginblue.com.au/Personal/Flightinfo/SpecialNeedsandAssistance/IndependentTrav elCriteria/index.htm

Wheelchair Accessible Taxi TaskForce. (2004). Interim Brief to the Minister for Transport Services. WHEELCHAIR ACCESSIBLE TAXI TASKFORCE. Retrieved 20 December 2007, from http://www.transport.nsw.gov.au/publications/WAT-interim-brief.pdf

Williams, R., \& Rattray, R. (2005). UK hotel web page accessibility for disabled and challenged users. Tourism \& Hospitality Research, 5(3), 255-267.

Williams, R., Rattray, R., \& Grimes, A. (2006). Meeting the On-line Needs of Disabled Tourists: an Assessment of UK-based Hotel Websites. International Journal of Tourism Research, 8(1), 59.

\section{Case Law}

Adams v Arizona Bay Pty. Ltd., Charlie Habib and Bunge Pty. Ltd. [1996], Unreported (Human Rights and Equal Opportunity Commission No. H.96/128).

Brandy v Human Rights and Equal Opportunity Commission [1995], PLPR 19 (High Court of Australia).

Brown V Birss Nominees Pty Ltd [1997], Unreported (Human Rights and Equal Opportunity Commission No. H.97/6).

Cocks $v$ the State of Queensland [1994], Unreported (Queensland Equal Opportunity Commission 92$612)$.

Cooper \& Others v Holiday Coast Cinema Centres Pty Ltd [1997], Unreported (Human Rights and Equal Opportunity Commission No. 96/157).

Cooper v Human Rights \& Equal Opportunity Commission [1999], Unreported (Federal Court of Australia 180).

Cooper, President North Coast D.I.A.L. Inc. v Coffs Harbour City Council [2000], Unreported (Human Rights and Equal Opportunity Commission No. H.97/232).

Francey \& Meeuwissen v Hilton Hotels of Australia Pty Ltd (Outcome) [2000], Unreported (Human Rights and Equal Opportunity Commission H97/50 \& H97/51).

Francey \& Meeuwissen v Hilton Hotels Of Australia Pty Ltd [1997], Unreported (Human Rights and Equal Opportunity Commission H97/50 \& H97/51).

Geoffrey Scott $v$ Telstra Corporation; DPI(A) and Australian Association of the Deaf $v$ Telstra Corporation [1997], Unreported (Human Rights and Equal Opportunity Commission).

Jennings v Lee [1996], Unreported (Human Rights and Equal Opportunity Commission No. H.96/3).

Kitt v Tourism Commissioner and Ors [1987], Unreported (NSW Equal Opportunity Commission EOC 92-196)

Maguire v Sydney Organising Committee for the Olympic Games (Internet) [2000], Unreported (Human Rights and Equal Opportunity Commission No H 99/115).

Maguire v Sydney Organising Committee for the Olympic Games (Ticket Book) [1999], Unreported (Human Rights and Equal Opportunity Commission No H 99/115).

McLean v. Airlines of Tasmania Pty Ltd [1996], Unreported (Human Rights and Equal Opportunity Commission No. H.96/77)

Pruszinski Architects v. the City of Adelaide (2001), Unreported (Environment Resources And Development Court - SA No. 84).

Wv P Pty Ltd [1997], Unreported (Human Rights and Equal Opportunity Commission No H95/133).

White v Crown Casinos Ltd. [1995], Unreported (Human Rights and Equal Opportunity Commission No. H.95/7). 